\title{
Solving the LEOT labor shortage
}

\section{Neal Miller}

Neal Miller, "Solving the LEOT labor shortage," Proc. SPIE 3831, Sixth International Conference on Education and Training in Optics and Photonics, (16 June 2000); doi: 10.1117/12.388696

Event: Education and Training in Optics and Photonics (ETOP'99), 1999, Cancun, Mexico 


\title{
Solving the LEOT Labor Shortage \\ Neal Miller, Optics \& Photonics Training Systems, Columbia, MO
}

\begin{abstract}
The demand for precision and efficiency is changing the way manufacturers are utilizing photonic and electro-optical technologies. This new demand has created a need for more specially trained operators than our post-secondary programs can supply.

An overlooked resource for solving industries personnel problems is the local tech prep high school. These programs already have (1) life-long learning, (2) making technology accessible, and (3) transition from school to work as goals. Tech prep schools already have $75 \%$ of the needed equipment in their electronic, computer and technology labs. Add the missing laser labs and you can start a Laser Electro-Optical Technician training program at the secondary level. This arrangement also makes it possible to launch a customized training program available to local industries to place LEOT's in their workforce in just 16 weeks.
\end{abstract}

Keywords: LEOT, electro-optical, lasers, photonics, workforce development, job training, CORD

\section{BACKGROUND}

The demands for efficiency and precision are causing manufacturers from an array of industries to turn to photonic and electro-optical technologies for solutions. Recently the National Research Council, in their report "Harnessing Light: Optical Science and Engineering for the 21st Century," put it even more strongly. They predict that "harnessing the properties of light will lead to a technology revolution having a pervasive impact on life in the next century." It is estimated that this will be a $\$ 500$ billion a year market by 2010.

\section{NATURE OF THE PROBLEM}

We are already experiencing a critical shortage of trained personnel. According to NIST, while the United States consumes approximately $\mathbf{4 0}$ percent of the products, it currently controls only 9 percent of the present $\$ 16$ billion photonics component manufacturing market and the gap is widening. Historically, America's technical and scientific education has been provided by a combination of three institutional groups: the military, colleges and universities, and vocational/technical schools, which combine both practical and academic job-training curricula. When specific training is not available in a particular field, private industry has closed the gap by providing in-house, privately funded job training. Unfortunately, this traditional mix will not be sufficient to fill the demand for hundreds of thousands of trained Laser Electro-Optical Technicians (LEOT) within the next few years.

To date the military has supplied most of industry's trained technical personnel. Due to military cutbacks, the model, which once provided the United States with a steady supply of equipment technicians, does not exist today, particularly with regard to photonics experts. Though some government funds are flowing toward research-related activities, fewer funds are being expended to broaden training courses in new technologies such as photonics.

As for colleges, universities and technical schools, fewer than 200 post-secondary educational institutions in the United States offer photonics courses as part of their regular curricula, and fewer than 20 offer twoyear LEOT programs. Even if every college and technical school with an existing laser program trained full classes of students each year, it would take nearly 200 years to fill the needs which industry will create by the year 2003. Simply stated, right now, post-secondary institutions can provide only about one half of one percent of the actual demand for LEOTs each year. Since most of these programs require two to four 
years of classroom instruction, the lag time in training far outstrips the realistic demands of the manufacturing sector. The current need is for 5,000 locations training LEOT's, not 200.

This also means that the traditional content-focused training for industry needs to be changed. It is not enough to know how to fix a problem; workers must know when and whether it is cost effective to do so. And because workers need to be able to visualize what is going on with this equipment without actually seeing it, at first the work appears half technology and half magic. These nanotechnology manufacturing systems, however, involve too many pieces for one person to juggle and too much information for one person to manage. This is why work at ten to the minus 9 requires life-long learning and team problem solving skills.

The old post-secondary training paradigm is woefully inadequate to solve these problems. Private industry is the only entity remaining which understands the problem and could effectively train and fill the demands for LEOTs in any realistic time frame. This forces major corporations to shoulder the primary responsibility for training the next generation of technical experts. While hundreds of U.S. companies are involved in various aspects of the photonics industry, only a few large companies have the ability to create their own programs and compete at the international level. The rest are limited by what NIST labels "the absence of a manufacturing infrastructure."

\section{SOLUTION}

However, an alternative model does currently exist. This program provides significant savings in retraining costs to the manufacturing company, incorporates cost sharing structures into the Tech Prep education programs, and introduces basic concepts of photonics and lasers to an increasingly younger audience.

First, the program shifts the focus of training to the more easily accessible and certainly more numerous high school laboratories, or to the Tech Prep schools, which have already realized the value of partnering with private businesses. This program also takes advantage of the significant investment that has already been made at the secondary level in facilities such as computer, electronics, and physics labs. These facilities can provide the venue for LEOT instruction. Furthermore, with private industry funding only the addition of laser labs, $100 \%$ of basic LEOT retraining could occur on the campuses of nearly every high school in this country. And because the OJT portion of these customized program occurs at the manufacturer's site, this eliminates the "conflict of interest" problem among the different manufacturers who would utilize these programs.

Second, the benefits of creating a public/private partnership between secondary schools and manufacturers are abundantly clear. The investment in scientific facilities and materials benefits both the manufacturer and the public school student. Manufacturers obtain a local, well-equipped training site, and public school systems realize enhanced educational facilities which can be employed in a regular high school curriculum without significant budget outlays.

Third, the introduction of a new technology into the public school's curricula will heighten awareness of photonics as a career opportunity in much the same way that the introduction of computer curricula affected the educational psyche of high school students during the 1980s. When high school students see adults from local industries taking Principles of Technology class in their high school, it speaks volumes as to the importance of this class and their future employment.

The students who benefit from the new facilities this public/private partnership provides will also find themselves ahead of the learning/employment curve should they decide to continue with a career in photonics. At the April 1999 Workforce Development workshop, Dr. Lester Lee and Dr. Victor Fishman talked about the advantages such programs provide for women, minorities and the physically challenged. These kinds of programs are essential for youth to see other role models and better employment 
possibilities than those which have traditionally existed. An important point made was that once students from these segments of our society finish secondary school, it is too late to recruit them.

Such a program has been operating at the Columbia Area Career Center in Columbia, Missouri, since 1995. The 16-week program Neal Miller designed for $3 \mathrm{M}$ included 8 weeks of classes at the Career Center, followed by 8 weeks of job site training, 3 weeks of which was classroom follow-up addressing specific production problems. The 16 weeks of classes were modified from existing LEOT and Tech Prep materials provided by CORD, incorporating additional critical team building and processing skills components.

$3 \mathrm{M}$ and the Career Center jointly developed a school site for this program. 3M provided funds for a new laser lab, and with some of the cost offset by matching state funds and training dollars, LEOTs were being trained at the Career Center by January 1995. By the end of the first year, two classes of $3 \mathrm{M}$ employees had completed the program, set up (installed) and qualified their excimer lasers (put into production), and each was on line manufacturing product in 16 weeks.

The course objectives were kept simple and straightforward. Operate equipment safely, demonstrate ability to work as a team to solve problems, and demonstrate proficiency with various laser applications. Communication skills and team problem solving skills were emphasized in every aspect of the training process.

In order to replicate this program, the approach also needs to be simple and straightforward. The materials are already available. The physics and laser classes used existing curricula materials from CORD. The computer classes used existing operating systems, word processing, spread sheet, data base managers, graphics, telecommunications, and web page management materials. The electronics and PLC classes used existing electronics materials. What needs to change is how we look at the problem and how we train people with these materials to be the kinds of technicians this industry needs. The success of the $3 \mathrm{M}$ program underscores this point. Through all these classes students were taught different strategies to use in solving different kinds of problems and how to solve the problems presented to them by their instructors as teams.

Over 5,000 high schools are available where this program could be implemented. First, using employees who want to change or who would be laid off during the next five years as the transitions are made to the new technologies. In the beginning the implementation would only be limited by geographical distribution of private companies who employ LEOTs in their own manufacturing process and their willingness to enter into such agreements.

The time constraints of this program forced us to focus on what we could do: teach strategies for using content rather than teaching the content itself. The careful combination of both practical and academic approaches helped in discussions with the basic problem solving and thinking exercises assigned and gave students the ability to apply academic knowledge to real-world settings. We assumed they would be able to solve any problem encountered on the job; so far they have proved this assumption correct. Their solutions to various problems are both unique and successful.

Since starting to train LEOTs for 3M using our customized 16-week fast-track program, our assumption about this program generating high school student interest has also proved true. Their demands have created three different courses for high school students and evening classes for adults.

Taking into account the widely documented fact that LEOTs will be in high demand in both the short and long term future, this model can insure that well-educated individuals will continually be available in adequate numbers to allow the implementation of new optical technologies.

This program is not intended to replace any traditional $2-4$ year educational program. But because the manufacturing paradigm has changed to shorter cycles and less lead time, profitability now requires life 
long learners who can upgrade or learn a new technology in two to eight weeks. When used to retrain present or potentially laid-off employees the manufacturer's cost for this program is minimal. Second, the manufacturer already has a local classroom ready for the next technology upgrade cycle. Third, when done at the high school instead of at the community college, it gets the next generation prepared for careers in this industry. It puts the latest technology in the public schools and teaches the next generation how it works. This private investment in public education is just the thing to prime the pump of a national program in photonics.

\section{REFERENCES}

CORD, Center for Occupational Research and Development, Waco, TX.

Darrell Hull and Nicholas Massa, "Workforce Development for Optics and Photonics," Optic \& Photonics News, September, pp23-29, 1998.

Neal Miller, "Public Education and Photonics," Optics \& Photonics News, February, pp49-50, 1999.

National Research Council, Harnessing Light: Optical Science and Engineering for the 21st Century, http://books.nap.edu/books/0309059917/html/R1.html\#R1.

NIST, Photonics Manufacturing 1998 Focused Program Paper, http://www.atp.nist.gov/atp/97wppm.htm.

Optics \& Photonics Training Systems Workshop, Workforce Development: When Training Becomes Education, Columbia, MO, April 1999. 